\title{
Phenotypic Variation Within a Clonal Lineage of Phytophthora infestans Infecting both Tomato and Potato in Nicaragua
}

\author{
J. U. Blandón-Díaz, A.-K. Widmark, A. Hannukkala, B. Andersson, N. Högberg, and J. E. Yuen
}

First author: Universidad Nacional Agraria, Apartado postal 453, Nicaragua and Swedish University of Agricultural Sciences, Department of Forest Mycology and Pathology, P.O. Box 7026, S-750 07 Uppsala, Sweden; second, fourth, fifth, and sixth authors: Swedish University of Agricultural Sciences, Department of Forest Mycology and Pathology; and third author: MTT Agrifood Research Finland, Plant Production Research, FI-31600 Jokioinen, Finland.

Accepted for publication 9 November 2011

\begin{abstract}
Blandón-Díaz, J. U., Widmark, A.-K., Hannukkala, A., Andersson, B., Högberg, N., and Yuen, J. E. 2012. Phenotypic variation within a clonal lineage of Phytophthora infestans infecting both tomato and potato in Nicaragua. Phytopathology 102:323-330.

Late blight caused by Phytophthora infestans (Mont.) de Bary is a constraint to both potato and tomato crops in Nicaragua. The hypothesis that the Nicaraguan population of $P$. infestans is genotypically and phenotypically diverse and potentially subdivided based on host association was tested. A collection of isolates was analyzed using genotypic markers (microsatellites and mitochondrial DNA haplotype) and phenotypic markers (mating type, virulence, and fungicide sensitivity). The genotypic analysis revealed no polymorphism in 121 of 132 isolates of $P$.

detected. Most of the tested isolates were resistant to metalaxyl. The virulence testing showed variation among isolates of $P$. infestans. No evidence was found of population differentiation among potato and tomato isolates of $P$. infestans based on the genotypic and phenotypic analysis. We conclude that the Nicaraguan population of $P$. infestans consists of a single clonal lineage (NI-1) which belongs to the A2 mating type and the Ia mitochondrial DNA haplotype. Moreover, based on the markers used, this population of $P$. infestans does not resemble the population in countries from which potato seed is imported to Nicaragua or the population in neighboring countries. The data presented here indicate that the NI-1 clonal lineage is the primary pathogen on both potato and tomato, and its success on both host species is unique in a South American context.
\end{abstract} infestans tested. Only the Ia haplotype and the A2 mating type were
Late blight caused by Phytophthora infestans (Mont.) de Bary is one of the main constraints to both potato and tomato crops in the northern highlands of Nicaragua, where weather conditions are conducive for the disease development from May to January. Despite this, no information has been available about the population biology and the underlying epidemiological implications of possible genotypic and phenotypic diversity of the pathogen in Nicaragua.

$P$. infestans is a diploid, hemibiotrophic, and heterothallic organism with two mating types designated A1 and A2. One hypothesis is that it originated and evolved in the central highlands of Mexico (26,41). However, recent studies have suggested a South American origin of P. infestans (28). Prior to the 1980s, worldwide populations of $P$. infestans were dominated by a single clonal lineage known as the US-1 "old" genotype, having the A1 mating type $(20,25)$. In contrast, in the Toluca Valley in central Mexico, the A1 and A2 mating types were present in approximately equal frequencies and the populations of $P$. infestans were entirely different from populations in other locations $(18,26)$. Since the mid-1980s, changes in the population structure of $P$. infestans outside Mexico have been reported (19). These changes brought about the displacement of the old genotype by a "new" genotype, which is characterized by both mating types and increased fitness and aggressiveness, as well as metalaxyl resistance (11). Moreover, the pathogen has been found to produce oospores under field conditions, which seem to be acting as initial inoculum in Northern Europe (2,3,37).

Corresponding author: J. E. Yuen; E-mail address: jonathan.yuen@ mykopat.slu.se

http://dx.doi.org/10.1094/PHYTO-02-11-0033

(c) 2012 The American Phytopathological Society
Populations of $P$. infestans have been characterized using a series of genotypic and phenotypic markers. Phenotypically, populations of $P$. infestans have been distinguished through determination of the mating type, virulence spectrum, and metalaxyl resistance (21). The genotypic characterization of $P$. infestans has included the use of allozyme patterns, mitochondrial DNA (mtDNA) haplotype determination, random amplified polymorphic DNA, amplified fragment length polymorphism, and random fragment length polymorphism fingerprints with the probe RG57, and results from these studies can reveal high population diversity (17). In comparison with the previously mentioned markers, simple-sequence repeat (SSR) markers (also referred to as microsatellites) now seem to offer the greatest potential across a wide range of applications (9). Over the past 10 years, SSR markers have been developed for the study of $P$. infestans (34-36). Some advantages of SSR markers are their repeatability and that genotyping can be conducted directly from infected tissue without the need for pathogen isolation and culture. In addition, these are codominant markers, which provide better resolution when used with diploid organisms such as $P$. infestans.

In Latin America, $P$. infestans populations have been extensively studied. In the Toluca Valley in central Mexico, $P$. infestans reproduces sexually and the two mating types (A1 and A2) are found in approximately equal frequencies. In other countries of the subcontinent, $P$. infestans appears to reproduce primarily asexually, although both mating types have been found in the same host species. However, some of these data must be interpreted carefully due to revisions in the taxonomy of $P$. infestans and closely related species (42). Initial studies in Ecuador reported the presence of two clonal lineages (EC-1 and US-1) of the A1 mating type (16). However, further studies revealed the occurrence of the two mating types (A1 and A2) of P. infestans sensu 
lato in Solanum muricatum (1) but the A2 isolate in that study was probably $P$. andina (42); in Peru, an A1 clonal population has been reported (44); in Brazil, the A1 and A2 mating types have been found in tomato and potato, respectively, but they have not been detected in the same field (46). In Uruguay, only the A2 mating type has been found (12); in Colombia, the A1 and A2 mating types have been found in the same host, Physalis peruviana (cape gooseberry), although no evidence of sexual recombination has been reported thus far (49); in Costa Rica, a clonal lineage of A1 mating type has been reported attacking potato; however, isolates of the A2 mating type have been also found in wild Solanum spp. (27). In Argentina, Phytophthora infestans populations seem to be more diverse when compared with other Latin American countries because both mating types have been found. However, Argentinean isolates of the A2 mating type have been found in a higher frequency and they showed greater aggressiveness and an increased resistance to metalaxyl compared with the A1 isolates (4). Clonality of $P$. infestans populations has been reported from Venezuela, where only the A1 mating type has been found (6).

Some degree of pathogenic specialization of $P$. infestans to potato or tomato has been reported. In a study carried out in Ecuador, it was found that there were two different clonal lineages of $P$. infestans separated by their host adaptation. The EC-1 clonal lineage was found on potato, while US-1 was found mainly on tomato (43). Recently, studies in Brazil demonstrated that isolates of $P$. infestans belonging to the US-1 clonal lineage were adapted to tomato, while the isolates of the BR-1 clonal lineage were adapted to potato $(46,48)$. In the United States, a study showed that potato and tomato populations of $P$. infestans had different genetic diversity and structure. Moreover, it was found that the tomato populations of $P$. infestans turned out to be more genetically diverse over time than potato populations (50). In contrast to this, a recent study carried out in Taiwan showed no host specificity on potato or tomato among $P$. infestans isolates from tomato (7). Thus, it is clear that there is no a general consensus about host specificity of $P$. infestans among scientific community.

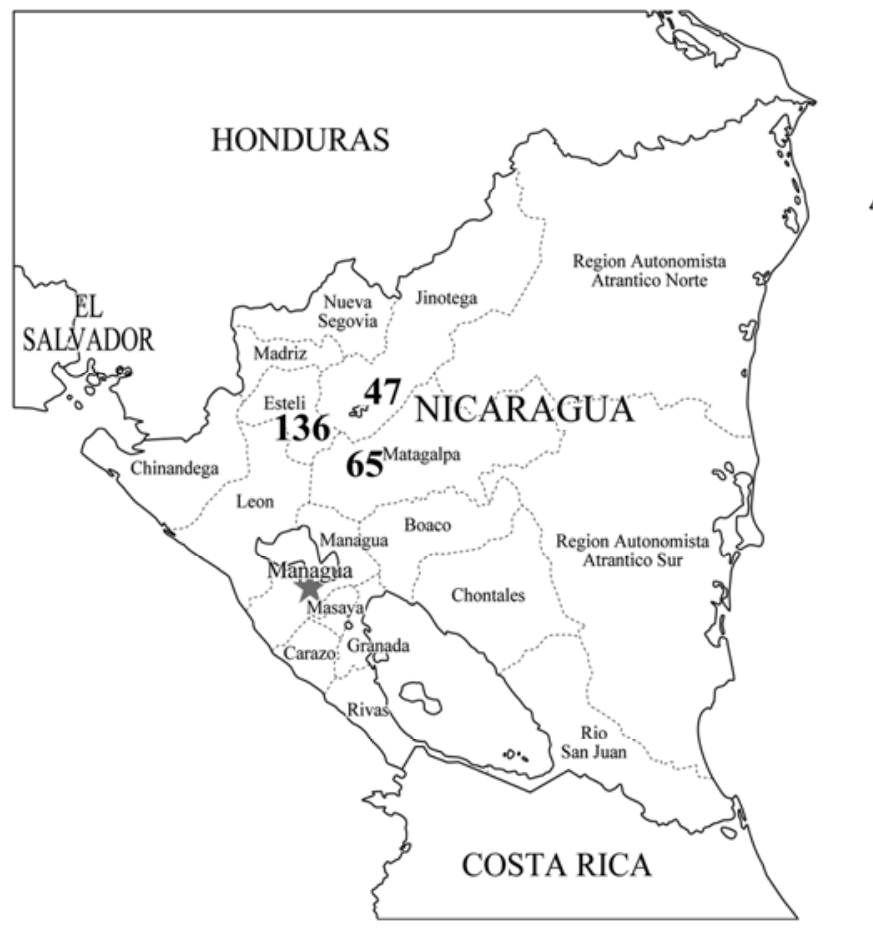

Fig. 1. Map of Nicaragua showing the three northern departments where isolates of Phytophthora infestans were collected from 2007 to 2010. The number of isolates collected in each department is indicated on the map.
It is believed that cultivated potato ( $S$. tuberosum) was introduced to Nicaragua in the early 1900s and, with it, the late blight pathogen. Troops from United States supposedly brought potato tubers for consumption, some of which fell into the hands of local people who began growing potato crops. Therefore it could be hypothesized that the first populations of $P$. infestans present in Nicaragua belonged to the old US-1 genotype of the A1 mating type and the Ib mtDNA haplotype (19). Moreover, this introduction would have occurred before the second worldwide migration of $P$. infestans that was thought to have taken place in the $1980 \mathrm{~s}$ (24).

Unlike other countries, Nicaragua does not have a well-established program for potato seed production; therefore, the country depends on the import of potato seed to meet the grower's demand. The potato seed is frequently imported from European countries such as The Netherlands, North America (United States and Canada), and Guatemala. If $P$. infestans is carried on the seed potato, one might expect variation in the pathogen population. In Nicaragua, potato production is concentrated in three northern departments (the Nicaraguan equivalent of a province): Estelí, Jinotega, and Matagalpa, where climatic conditions are optimal for potato growth but also for late blight development. The disease also affects tomato in this region but the two crops are rarely grown in the same field. In this study, the hypothesis that the Nicaraguan population of $P$. infestans is genotypically and phenotypically diverse and potentially subdivided based on host association was tested. Thus, the strategy was to sample $P$. infestans in those regions of northern Nicaragua where both potato and tomato cultivation occurs along with the late blight pathogen. Isolates collected from both tomato and potato were analyzed using genotypic markers (SSR and mtDNA haplotyping) and phenotypic markers (mating type, virulence, and fungicide sensitivity).

\section{MATERIALS AND METHODS}

Sampling and isolation of $\boldsymbol{P}$. infestans. Leaflets of potato and tomato with a single late blight lesion were collected from commercial production and experimental fields in northern Nicaragua from July 2007 to January 2010. In each department, five to seven locations were sampled, taking a different number of samples from each location (Fig. 1). In all, 13 tomato and 43 potato fields (56 fields in total) located in 18 sites in three northern departments of Nicaragua were sampled (Table 1). Leaflets with single lesions were washed with distilled water and dried with filter paper. Thereafter, they were individually placed abaxial side up in a sealed petri dish containing a layer of $1.5 \%$ water agar and incubated at $18^{\circ} \mathrm{C}$ to promote sporulation. When sporulation was observed, the mycelia with sporangia was transferred to a pea agar medium (13) amended with antibiotics (ampicillin at $0.2 \mathrm{~g}$ liter $^{-1}$ and pimaricin at $10 \mathrm{mg}$ liter $^{-1}$ ) and incubated at $18^{\circ} \mathrm{C}$ in darkness for a week. Plugs of agar with growing hyphal tips were cut from the colony margins and transferred to petri dishes with pea agar medium without antibiotics and incubated at $18^{\circ} \mathrm{C}$ for growth and sporulation. Axenic isolates were maintained on pea agar medium without antibiotics and transferred monthly to fresh medium. Additionally, 54 single lesion-blighted potato and tomato leaflets were preserved as dried material for DNA extraction.

DNA extraction. Two approaches were used to extract DNA for mitochondrial haplotyping and microsatellite analysis, depending on whether the sample was stored as lyophilized mycelium or as dried leaflets. Individual pieces of lyophilized mycelium were placed in a 2-ml polypropylene vial containing six glass beads and homogenized in a FastPrep preparation shaker (Precellys 24; Bertin Technologies). DNA was extracted following the protocol provided with the Wizard Genomic DNA purification kit: protocol for plant tissue (Promega Corp.) for isolating genomic DNA from plant tissue. Dried leaflets of potato and tomato infected with $P$. infestans were homogenized for DNA extraction as described for 
lyophilized mycelium. DNA from dried leaflets was extracted using a cetyltrimethylammonium bromide (CTAB) procedure (22), with the exception that $3 \%$ CTAB was used.

Genotypic analysis. mtDNA haplotyping. mtDNA haplotyping was carried out using a method described earlier (29), with slight modifications. The annealing temperature was increased to $63^{\circ} \mathrm{C}$ and the primer pairs $\mathrm{P} 2$ and $\mathrm{P} 4$ were used at a concentration of $0.4 \mu \mathrm{M}$.

Microsatellite analysis. Seven SSR primers were used for the microsatellite analysis of 132 isolates of $P$. infestans: Pi4B, PiG11 (35), Pi16, Pi70, PiD13, Pi63, and Pi04 (36). Forward primers 4B, Pi16, D13, and Pi04 were labeled with 6-FAM (TAG Copenhagen), whereas G11, Pi70, and Pi63 were labeled with NED (Applied Biosystems). Polymerase chain reaction (PCR) amplifications were performed in $15 \mu \mathrm{l}$ containing approximately $10 \mathrm{ng}$ of genomic DNA, $0.2 \mathrm{mM}$ dNTPs, $0.4 \mu \mathrm{M}$ each forward and reverse primers, ThermoRed DNA polymerase (Saveen \& Werner

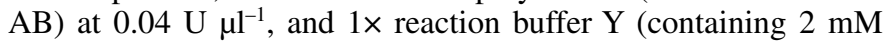
$\mathrm{MgCl}_{2}$ ) supplied by the manufacturer. For the primers for locus 4B and Pi70, $4 \mathrm{mM} \mathrm{MgCl} 2$ was used. The PCR conditions were as follows: an initial denaturation at $94^{\circ} \mathrm{C}$ for $3 \mathrm{~min}$; followed by 30 or 33 cycles (dependent on the primers) at $94^{\circ} \mathrm{C}$ for $30 \mathrm{~s}, 30 \mathrm{~s}$ of annealing temperature of 50 to $62^{\circ} \mathrm{C}$ dependent on the primers, and elongation at $72^{\circ} \mathrm{C}$ for $1 \mathrm{~min}$; and final extension at $72^{\circ} \mathrm{C}$ for 25 min (GeneAmp PCR System 2700; Applied Biosystems). The annealing temperature and the number of cycles for each primer were as follows: $50^{\circ} \mathrm{C}$ and 33 cycles for primer $\mathrm{D} 13,58^{\circ} \mathrm{C}$ and 33 cycles for primers $\mathrm{Pi} 4 \mathrm{~B}$ and $\mathrm{Pi} 70,60^{\circ} \mathrm{C}$ and 30 cycles for Pi63, $60^{\circ} \mathrm{C}$ and 33 cycles for Pi16, and $62^{\circ} \mathrm{C}$ and 30 cycles for primers PiG11 and Pi04. For dried leaflet samples, the annealing temperature and the number of cycles for primer Pi63 were $58^{\circ} \mathrm{C}$ and 33 cycles, respectively. Separation of the amplified fragments was done using an ABI 3730xl DNA analyzer at Uppsala Genome Center, Rudbeck Laboratory, Uppsala University in Sweden. The fragment length of the fluorescently labeled fragments was visualized and scored using the software GeneMarker version 1.6 (Softgenetics). The allele sizes were adjusted to the sizes obtained at SCRI (36) by comparison with reference isolates, kindly supplied by Drs. Lee and Cooke, SCRI.

Phenotypic analysis. Mating type determination. Mating type determination was made using tester isolates of known mating type (A1 or A2) and the unknown Nicaraguan isolates. Mycelial plugs $(0.5 \mathrm{~cm}$ in diameter $)$ of each were placed in petri dishes containing rye pea agar (38) and incubated at $20^{\circ} \mathrm{C}$ in the dark. Cultures were examined for oospore formation in the zone of interaction. After 2 weeks, the mating type of the unknown isolate was recorded as the opposite of the tester isolate with which it formed oospores. In the mating type assays, 248 Nicaraguan isolates of $P$. infestans were tested.

Fungicide sensitivity, and virulence tests. The fungicide sensitivity of the isolates to metalaxyl-M and propamocarb hydrochloride (propamocarb- $\mathrm{HCl}$ ) was determined using the floating leaf disc method $(38,47)$. For virulence testing, a procedure described earlier (38) was followed. Only potato plants with resistance genes were used for virulence tests, because no tomato differentials were available. Mean number of virulence factors per isolate $(C i)$ and race $(C p)$ was calculated (5). The $C i$ and $C p$ were separately calculated for the potato and tomato isolates. Moreover, to detect differences among potato and tomato isolates, a $t$ test procedure with the $C i$ and $C p$ values was performed.

\section{RESULTS}

Sampling and isolation of $\boldsymbol{P}$. infestans. Of the sampled isolates, $84 \%$ (209 isolates) were isolated from blighted potato leaflets and 16\% (39 isolates) were isolated from blighted tomato leaflets and fruits. All of the 248 collected isolates were tested for mating type, and a subset of 132 isolates was used for micro-

TABLE 1. Origin, mating type, mitochondrial DNA haplotype, and simple-sequence repeat (SSR) fingerprinting pattern of Phytophthora infestans isolates collected from 2007 to 2010 in northern Nicaragua ${ }^{a}$

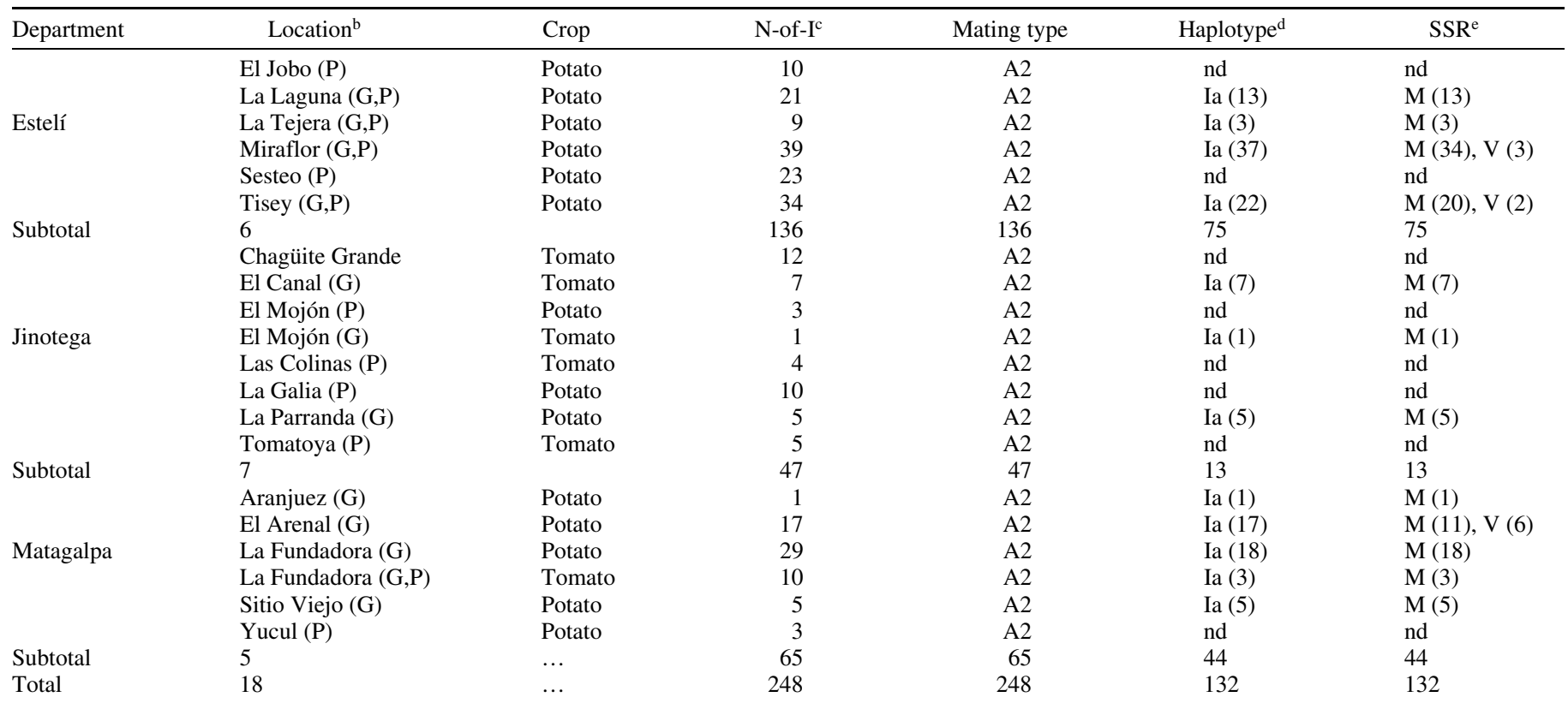

a Abbreviation: nd = not determined or not included in the analysis.

${ }^{\mathrm{b}}$ Isolates collected from locations marked with the letters $\mathrm{G}$ and $\mathrm{P}$ were used for genotypic $(\mathrm{G})$ and phenotypic $(\mathrm{P})$ analyses. In some cases, the isolates were collected from the same location for both analyses (G,P).

${ }^{c}$ Number of isolates collected from 2007 to 2010 in the main potato growing areas of northern Nicaragua.

${ }^{\mathrm{d}}$ Mitochondrial DNA haplotype. Numbers in parenthesis indicate the number of isolates that were tested.

${ }^{\text {e }}$ SSR = simple sequence repeats (also known as microsatellites). $\mathrm{M}=$ monomorphic for SSR markers. Numbers in parenthesis indicate the number of isolates that were included in the analysis. V = variants, those isolates that showed a one-step difference at loci G11 and Pi16. For instance, in location Miraflor, two isolates had a one-step difference at locus G11 and one isolate showed a one-step difference at locus Pi16. On the other hand, in other locations, such as Tisey and El Arenal, variation was observed only at locus G11. 
satellite analysis and mtDNA haplotyping. In all, 98 isolates (82 from potato and 16 from tomato) were tested for fungicide sensitivity and used in virulence tests. Isolates for genotypic and phenotypic analyses were collected from 11 and 12 locations, respectively (Table 1$)$.

Genotypic analysis. Overall, SSR genotyping using the set of seven primers (4B, G11, Pi16, Pi70, D13, Pi63, and Pi04) revealed no polymorphism in 121 of 132 isolates of $P$. infestans from Nicaragua. The only exception to this was two rare genotypes that showed one-step difference at the loci Pi16 and G11 when compared with the commonly found genotype. Differences at the loci Pi16 and G11 were found in 1 and 10 potato isolates, respectively, representing $0.7 \%$ for the locus Pi16 and $7.6 \%$ for the locus $\mathrm{G} 11$ of the total isolates tested. These 11 potato isolates were collected from three different locations (El Arenal, Miraflor, and Tisey). Otherwise, all the other isolates from potato and tomato belonged to a single multilocus genotype. This dominant genotype was heterozygous for almost all the analyzed loci $(4 \mathrm{~B}$, 205/213; G11, 132/156; D13, 98/108; Pi63, 148/157; and Pi04, 166/170), except for loci Pi16 (176/176) and Pi70 (192/192). Minor variants of this genotype were found, with 176/174 at Pi16 (1 isolate) and 132/154 at G11 (10 isolates). mtDNA haplotyping revealed that all 132 isolates tested had the Ia haplotype (Table 1).
No evidence was found of population differentiation among potato and tomato isolates of $P$. infestans based on the SSR fingerprinting patterns and $\mathrm{mtDNA}$ haplotyping.

Phenotypic analysis. All of the isolates collected from different locations in northern Nicaragua were characterized as the A2 mating type (Table 1). In total, 96 isolates (including both potato and tomato isolates) were resistant to metalaxyl (98\%), 1 showed an intermediate reaction (1\%), and 1 was sensitive to metalaxyl (1\%) (Table 2; Fig. 2). The latter two were potato isolates. In all, $53(54 \%)$ were able to sporulate in propamocarb- $\mathrm{HCl}$ at 10 $\mathrm{mg} / \mathrm{liter}, 27$ isolates $(28 \%)$ sporulated in propamocarb- $\mathrm{HCl}$ at 100 $\mathrm{mg} / \mathrm{liter}, 18$ isolates $(18 \%)$ grew only in the control, and no isolate was able to sporulate at 1,000 mg/liter (Fig. 2).

The results from the virulence testing showed variation among isolates of $P$. infestans from Nicaragua. Among the 82 potato isolates, 31 races were found. The most frequent race in the potato isolates was R1.2.3.4.5.6.7.10.11 (14 isolates), followed by $\mathrm{R} 1.2 .3 .4 .6 .7 .10 .11$ (9 isolates), $\mathrm{R} 1.3 .4 .5 .7 .10 .11$ (7 isolates), R1.3.4.7.11 (6 isolates), and R1.3.4.7 (5 isolates). Fifteen races were represented by a unique isolate, whereas the remaining races (11) were represented by two or four isolates (Table 2). Among the 16 tomato isolates, 11 races were identified; that is, almost 1 race per isolate tested. The most frequent races found in tomato

TABLE 2. Race structure and response to metalaxyl-M of Phytophthora infestans isolates collected from potato and tomato plants during 2008 and 2009 in the main potato- and tomato-growing areas of Nicaragua

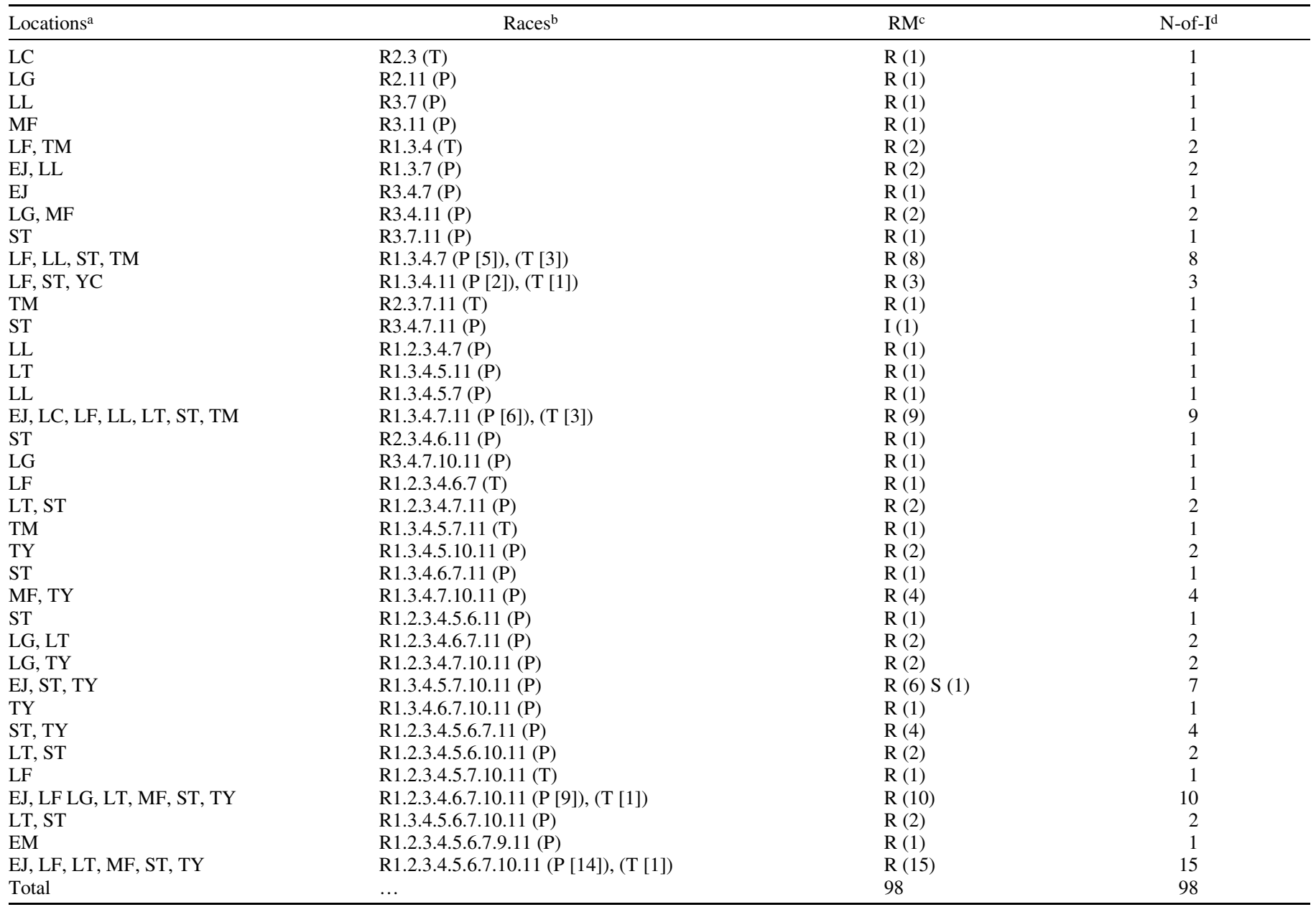

${ }^{\mathrm{a}}$ EJ $=$ El Jobo, EM = El Mojón, LC $=$ Las Colinas, LF = La Fundadora, LG = La Galia, LL = La Laguna, LT = La Tejera, MF = Miraflor, ST = Sesteo, TM = Tomatoya, $\mathrm{TY}=$ Tisey, and $\mathrm{YC}=$ Yucul.

${ }^{\mathrm{b}}$ The host origin of the isolates belonging to each race is indicated by the letter $\mathrm{P}$ (potato plants) and $\mathrm{T}$ (tomato plants); numbers in brackets indicate the number of isolates sampled from each host plant and used for virulence testing.

${ }^{\mathrm{c}} \mathrm{RM}=$ response to metalaxyl-M; $\mathrm{R}$ = resistant, $\mathrm{I}=$ intermediate resistant, and $\mathrm{S}=$ susceptible. Numbers in parenthesis indicate the number of isolates in each category. The susceptible isolate was collected in location Tisey.

${ }^{\mathrm{d}} \mathrm{N}$-of-I = number of potato and tomato isolates used in fungicide sensitivity tests and in virulence testing using the potato differential set of resistance $(R)$ genes (R1 to $R 11)$. 
isolates were R1.3.4.7. (three isolates) and R1.3.4.7.11 (three isolates) followed by R1.3.4 (two isolates). The remaining tomato races were each represented by a unique isolate (Table 2 ). Both potato and tomato isolates overcame resistance gene R1 at the same proportion $(88 \%)$. The remaining resistance genes were overcome at different proportions depending on the source (tomato or potato) of the isolate tested. Only one potato isolate collected during 2008 was able to overcome resistance gene R9 and no isolate examined was able to overcome the resistance gene R8 (Fig. 3). The number of virulence factors in each isolate was 2 to 9 in both potato or tomato isolates. Among the potato isolates, 17 (grouped in four races) were found to have eight virulence factors. The $C i$ and $C p$ were 6.4 and 5.5, respectively, for potato isolates whereas, for tomato isolates, $C i$ and $C p$ were 5.0 and 5.4, respectively. The $C i$ was higher than $C p$ in potato isolates, indicating that complex races predominate within potato populations of $P$. infestans from Nicaragua. The number of tomato isolates was low compared with the number of potato isolates but there was a tendency of a higher number of simpler races in the tomato isolates. Nonetheless, the $t$ test procedure showed no significant differences between potato and tomato isolates for the $C i$ and $C p$ values (data not shown).

\section{DISCUSSION}

Genotypic diversity within populations of $P$. infestans from Nicaragua was expected due to the fact that potato seed is imported from the Netherlands, Canada, the United States, and Guatemala. Contrary to this initial hypothesis, the P. infestans population from Nicaragua seems to belong to a single clonal lineage having the A2 mating type and the Ia mtDNA haplotype. Our results indicate that the Nicaraguan clonal lineage of $P$. infestans does not originate from seed imported from The Netherlands or other European sources, because the allele with the size $132 \mathrm{bp}$ found at the locus G11 has not been recorded in European populations (D. Cooke, personal communication). This clonal lineage is not US-8, either, because that clonal lineage has a different genotype based on these microsatellite loci (D. Cooke, personal communication). The allele size $132 \mathrm{bp}$ at G11 has been found in a $P$. infestans strain from Mexico (www.euroblight.net) and has been recorded from A1 tomato isolates from the United States such as US-11 and US-12 (D. Cooke, personal communication), suggesting a New World origin of the Nicaraguan population. In studies carried out in Venezuela using 4B and G11 SSR markers (6) and Colombia using 4B and D13 markers (49), a similar low genotypic diversity was found among the tested $P$. infestans isolates. In Central America, the Nicaraguan population of $P$. infestans is of different mating type than the $P$. infestans populations in the neighboring countries. Transfer of agricultural products occurs over the borders of Nicaragua, Costa Rica, and Honduras and one might expect that isolates of $P$. infestans population from these countries might have entered Nicaragua or vice versa. Nonetheless, there is no indication from the data presented here that such a transfer has taken place. The Costa Rican population of $P$. infestans belongs to two clonal lineages with the A1 mating type in potato and the A2 mating type in wild Solanum spp. (27), while the $P$. infestans population from Honduras belongs to a clonal lineage having the A1 mating type (15). We are not aware of any publications about the population genetic structure of $P$. infestans from Guatemala and El Salvador.

These data suggest that $P$. infestans populations have experienced a major shift since their first appearance in Nicaraguan potato fields. The Ia and IIb mtDNA haplotypes have been found in herbarium specimens from Nicaragua dating from 1954 and 1956, respectively (39). In the present study, however, the IIb mtDNA haplotype was not found, indicating that it was completely replaced by the Ia mtDNA haplotype.

Despite low genotypic variability, the Nicaraguan population of $P$. infestans was found to be variable with regard to virulence spectra and fungicide resistance. This is in agreement with the results from a similar study conducted in Northern China, in which low genotypic diversity was observed, while the virulence spectra turned out to be highly variable. Moreover, in that study, it was

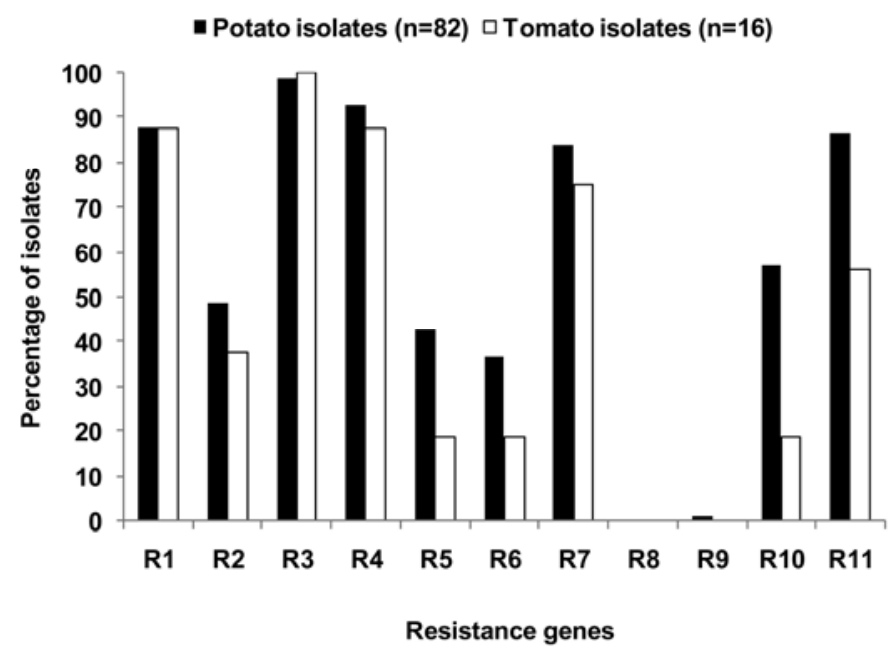

Fig. 3. Percentages of Phytophthora infestans isolates from Nicaragua overcoming resistance $(R)$ genes $(R 1$ to $R 11)$ from samples taken during 2008 and 2009 in potato (black bars) and tomato (white bars) fields.
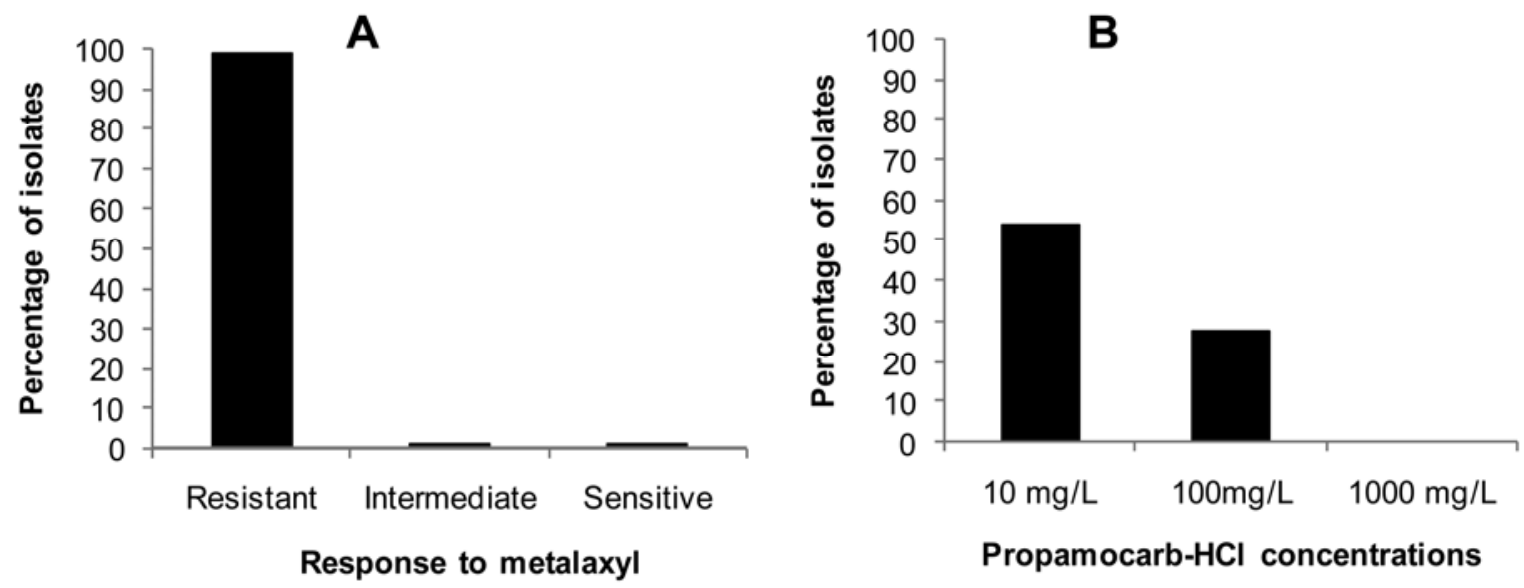

Fig. 2. Response of Phytophthora infestans isolates from Nicaragua (sampled in 2008-09) to A, phenylamide fungicide metalaxyl and B, propamocarb-HCl. Samples were taken from tomato and potato fields in different locations in northern Nicaragua. 
also found that some of the tested isolates were virulent to all resistance $(R)$ genes (32). However, unlike the Chinese population of $P$. infestans, the Nicaraguan one could not overcome all of the $R$ genes present in the traditional differential set of potato clones, and the most complex and most common races of $P$. infestans population overcame eight and nine resistance genes, respectively. A complex race structure and high virulence diversity have been detected in other parts of the world $(12,38,44)$. The resistance genes $R 1, R 3, R 4$, and $R 7$ are the ones most frequently overcome by the Nicaraguan potato isolates. The same trend was observed among tomato isolates. This is in agreement with the Euroblight data base of 4,349 isolates, where virulence frequencies of $>80 \%$ are reported for genes $R 1, R 3, R 4, R 7$, and $R 11$ (www.euroblight. net). Race complexity observed in $P$. infestans isolates from Nicaragua can have arisen as a result of the selection pressure imposed by potato cultivars carrying different $R$ genes. For example, 'Santé' potato, which is the preferred cultivar among Nicaraguan potato growers, is known to carry the resistance genes $R 1$ and $R 10$ (14), and this may be responsible, in part, for the high frequency of virulence to these resistance genes. The appearance of new races is related to mutations in avirulence (Avr) genes encoding effector proteins in such a way that the effectors are not able to be recognized by the $\mathrm{R}$ protein (32). Because the $A v r$ genes are localized in a hypervariable region of the genome (33), this could explain the high virulence diversity in isolates with the same SSR multilocus genotype.

Currently, metalaxyl-containing products are rarely applied in Nicaragua, if at all. Despite this, a high percentage of the tested isolates were resistant to metalaxyl. In other places around the world, a high percentage of $P$. infestans isolates resistant to metalaxyl has also been found $(8,12,45)$. In contrast, in a study carried out recently in Scandinavian countries, a decrease in the proportion of metalaxyl-resistant isolates compared with the early 1990s was observed (38). This decline in the proportion of isolates resistant to metalaxyl was attributed to a limited use of this fungicide in these countries. Resistance to phenylamide fungicides, such as metalaxyl, can naturally occur as a result of random mutation $(10,23)$. Nonetheless, preexisting resistant individuals increase in frequency as a result of the selection pressure imposed by fungicide application $(23,31)$. In Nicaragua, the appearance and increase of metalaxyl-resistant isolates probably occurred in the 1980s and early 1990s, when the potato production areas increased in size and metalaxyl-based fungicides were used frequently and indiscriminately. Therefore, this could have led to a directional selection toward resistance which persists in the current clonal Nicaraguan population of $P$. infestans. This could also result in a reduction in genotypic diversity, as has been reported in other studies (31). In spite of the infrequent use of metalaxyl, the phenotypic trait of metalaxyl resistance remains at a high frequency in the Nicaraguan population of $P$. infestans. This may be explained by a clonal population, which will retain unnecessary traits longer than a sexually reproducing population.

In this study, the sensitivity of Nicaraguan isolates of $P$. infestans against propamocarb hydrochloride was also tested. This fungicide is used by Nicaraguan potato growers formulated alone or as a mixture with other fungicides with different modes of action. As was pointed out earlier, no evidence of resistance to propamocarb- $\mathrm{HCl}$ was found when these isolates were exposed to the highest concentration $(1,000 \mathrm{mg} / \mathrm{liter})$ of the fungicide. Potato growers in Nicaragua apply propamocarb- $\mathrm{HCl}$ at a dose of 1,083 $\mathrm{mg} /$ liter active ingredient (a.i.) when formulated alone and 564 $\mathrm{mg} /$ liter a.i. when formulated as a mixture with another fungicide. Although $28 \%$ of the tested isolates were able to sporulate in propamocarb- $\mathrm{HCl}$ at a concentration of $100 \mathrm{mg} / \mathrm{liter}$ a.i., the lower fungicide dose applied by potato growers in the field is five times greater than that in which sporulation was detected. There are some reports from other parts of the world of $P$. infestans isolates resistant to propamocarb- $\mathrm{HCl}(38,40)$.
In the present study, based on the SSR analysis and mtDNA haplotyping, no genotypic difference was found between potato and tomato isolates of $P$. infestans. In studies addressing host specificity of $P$. infestans using phenotypic and genotypic markers, it has been found that populations on tomato often are different from those on potato. Tomato isolates from South America are associated with the US-1 clonal lineage $(43,48)$. On the other hand, one United States study reported that tomato isolates were more genetically diverse than those from potato (50). The data presented here indicate that the NI-1 clonal lineage has completely replaced the old genotypes and is the primary pathogen on both potato and tomato. For this reason, the success of NI1 clonal lineage on both host species is unique in a South American context. No aggressiveness tests were carried out in this study and, therefore, it is not known whether there are differences between potato and tomato isolates with regard to aggressiveness on the two host plants. Inclusion of the differentials for determining tomato races of $P$. infestans may have provided information as to any specialization but these were not available at the time of this study.

Although migrations of both mating types of $P$. infestans have made sexual reproduction of the pathogen theoretically possible, clonal lineages seem to dominate in most Latin American countries. This may be due to the fact that, in some Latin American regions (except the Toluca valley in Mexico), the climate is mild, there is a continuous potato production throughout the year, and there are more host plants available for the pathogen (including native solanaceous plants). It is also possible that, in these regions dominated by clonal lineages of $P$. infestans, antagonistic microbial processes limit the survival of oospores. In contrast, in the Toluca valley in central Mexico, there is substantial variation due to sexual reproduction (30). The high variation resulting from sexual reproduction of the pathogen could be due to a number of factors, including more seasonal production of potato in the Toluca valley versus continuous production in other Latin American countries. Moreover, the unique weather conditions (cool and dry climate) prevailing in the Toluca valley seems to favor the survival of the sexual structures (oospores) of $P$. infestans and foster sexual reproduction of the pathogen in that part of the world $(30,51)$.

In conclusion, the current Nicaraguan population of $P$. infestans consists of a single clonal lineage (NI-1), which belongs to the A2 mating type and the Ia mtDNA haplotype. Moreover, based on SSR markers, this population does not resemble the $P$. infestans population of those countries which provide the potato tuber seed planted in Nicaragua. With regard to mating type, the Nicaraguan population of $P$. infestans is different from that of neighboring countries such as Costa Rica and Honduras. However, the Nicaraguan population of $P$. infestans is highly variable regarding race composition and has a high frequency of individuals resistant to metalaxyl. Unlike other countries in Latin America, this clonal lineage appears to dominate in both potato and tomato crops. The tools used in this study were not able to distinguish between the potato and tomato isolates, and it is not known if there are differences in aggressiveness between these isolates, though they share a common ancestry. Moreover, important issues such as survival of $P$. infestans from season to season, sources of primary inoculum that initiate epidemics at the beginning of the growing season as well as their competition, and the role of the native solanaceous plants as a reservoir of inoculum remain unknown and could clarify the reasons behind the survival and persistence of this clonal lineage despite probable incursions by other genotypes.

\section{ACKNOWLEDGMENTS}

We thank the Swedish International Development Agency, the Swedish Agency for Research Cooperation with Developing Countries, and the 
Swedish Institute for invaluable contribution and funding; and A. Lees and D. Cooke (Scottish Crop Research Institute, Dundee) for providing reference isolates of $P$. infestans.

\section{LITERATURE CITED}

1. Adler, N. E., Chacón, G., Flier, W. G., and Forbes, G. A. 2002. The Andean fruit crop, pear melon (Solanum muricatum) is a common host for A1 and A2 strains of Phytophthora infestans from Ecuador. Plant Pathol. 51:802.

2. Andersson, B., Sandström, M., and Strömberg, A. 1998. Indications of soilborne inoculum of Phytophthora infestans. Potato Res. 41:305-310.

3. Andersson, B., Widmark, A.-K., Yuen, J. E., Kessel, G. J. T., Evenhuis, A., Turkensteen, L. J., Hannukkala, A., Lehtinen, A., Nielsen, B., Ravnskov, S., Hansen, J. G., Hermansen, A., Brurberg, M.-B., and Nordskog, B. 2009. The role of oospores in the epidemiology of potato late blight. Acta Hortic. 834:61-68.

4. Andreu, A. B., Caldiz, D. O., and Forbes, G. A. 2010. Phenotypic expression of resistance to Phytophthora infestans in processing potatoes in Argentina. Am. J. Potato Res 87:177-187.

5. Andrivon, D. 1994. Race structure and dynamics in populations of Phytophthora infestans. Can. J. Bot. 72:1681-1687.

6. Briceño, A., Cedeño, L., San Román, M., Moreno, M., Quintero, K., Pino, H., and Fermin, G. 2009. Population structure of Phytophthora infestans in the Venezuelan Andes (2004-2007). Acta Hortic. 834:129-140.

7. Chen, C.-H, Sheu, Z.-M., and Wang, T.-C. 2008. Host specificity and tomato-related race composition of Phytophthora infestans isolates in Taiwan during 2004 and 2005. Plant Dis. 92:751-755.

8. Chen, C.-H, Wang, T.-C, Black, L., Sheu, Z.-M., Perez, F., and Deahl, K. 2009. Phenotypic and genotypic changes in the Phytophthora infestans population in Taiwan-1991 to 2006. J. Phytopathol. 157:248-255.

9. Cooke, D. E. L., and Lees, A. K. 2004. Markers, old and news, for examining Phytophthora infestans diversity. Plant Pathol. 53:692-704

10. Dagget, S. S., Götz, E., and Therrien, C. D. 1993. Phenotypic changes in populations of Phytophthora infestans from eastern Germany. Phytopathology 83:319-323.

11. Day, J. P., and Shattock, R. C. 1997. Aggressiveness and other factors relating to displacement of populations of Phytophthora infestans in England and Wales. Eur. J. Plant Pathol. 103:379-391.

12. Deahl, K. L., Pagani, M. C., Vilaro, F. L., Perez, F. M., Moravec, B., Cooke, L. R. 2003. Characteristics of Phytophthora infestans isolates from Uruguay. Eur. J. Plant Pathol. 109:277-281.

13. Flier, W. G., Grünwald, N. J., Kroon, L. P. N. M., Sturbaum, A. K., van den Bosch, T. B. M., Garay-Serrano, E., Lozoya-Saladaña, H., Fry, W. E., and Turkensteen, L. J. 2003. The population structure of Phytophthora infestans from the Toluca Valley of Central Mexico suggests genetic differentiation between populations from cultivated potato and wild Solanum spp. Phytopathology 93:382-390.

14. Flier, W. G., Kroon, L. P. N. M., Hermansen, A., van Raaij, H. M. G., Speiser, B., Tamm, L., Fuchs, J. G., Lambion, J., Razzaghian, J., Andrivon, D., Wilcockson, S., and Leifert, C. 2007. Genetic structure and pathogenicity of populations of Phytophthora infestans from organic potato crops in France, Norway, Switzerland and the United Kingdom. Plant Pathol. 56:562-572.

15. Forbes, G. 2004. Global overview of late blight. Pages 3-10 in: Proc. Regional Workshop Potato Late Blight East and Southeast Asia and the Pacific. C. Lizarraga, ed. Yezin, Myanmar.

16. Forbes, G. A., Escobar, X. C., Ayala, C. C., Revelo, J., Ordoñez, M. E., Fry, B. A., Doucett, K., and Fry, W. E. 1997. Population genetic structure of Phytophthora infestans in Ecuador. Phytopathology 87:375-380.

17. Forbes, G. A., Goodwin, S. B., Drenth, A., Oyarzun, P., Ordonez, M. E., and Fry W. E. 1998. A global marker database for Phytophthora infestans. Plant Dis. 82:811-818.

18. Fry, W. 2008. Phytophthora infestans: The plant (and $R$ gene) destroyer. Mol. Plant Pathol. 9:385-402.

19. Fry, W. E., and Goodwin, S. B. 1997. Re-emergence of potato and tomato late blight in the United States. Plant Dis. 81:1349-1357.

20. Fry, W. E., and Goodwin, S. B. 1997. Resurgence of the Irish potato famine fungus. BioScience 47:363-371.

21. Fry, W. E., Goodwin, S. B., Dyer, A. T., Matuszak, J. M., Drenth, A., Tooley, P. W., Sujkowsky, L. S., Koh, Y. J., Cohen, B. A., Spielman, L. J., Deahl, K. L., Inglis, D. A., and Sandlan, K. P. 1993. Historical and recent migrations of Phytophthora infestans: Chronology, pathways, and implications. Plant Dis. 77:653-661.

22. Gardes, M., and Bruns, T. D. 1993. ITS primers with enhanced specificity of basidiomycetes: Application to the identification of mycorrhizae and rusts. Mol. Ecol. 2:113-118.

23. Gisi, U., and Cohen, Y. 1996. Resistance to phenylamide fungicides: A case study with Phytophthora infestans involving mating type and race structure. Annu. Rev. Phytopathol. 34:549-572.

24. Goodwin, S. B., Cohen, B. A., Deahl, K. L., and Fry, W. E. 1994. Migration from northern Mexico as the probable cause of recent genetic changes in populations of Phytophthora infestans in the United States and Canada. Phytopathology 84:553-558.

25. Goodwin, S. B., Cohen, B. A., and Fry, W. E. 1994. Panglobal distribution of a single clonal lineage of the Irish potato famine fungus. Proc. Natl. Acad. Sci. USA 91:11591-11595.

26. Goodwin, S. B., Spielman, L. J., Matuszak, J. M., Bergeron, S. N., and Fry, W. E. 1992. Clonal diversity and genetic differentiation of Phytophthora infestans populations in northern and central Mexico. Phytopathology 82:955-961.

27. Gómez-Alpizar, L. 2004. Molecular evolution of Phytophthora infestans (Mont.) de Bary, the late blight pathogen. PhD thesis, North Carolina State University, NC.

28. Gómez-Alpizar, L., Carbone, I., and Ristaino, J. B. 2007. An Andean origin of Phytophthora infestans inferred from mitochondrial and nuclear gene genealogies. Proc. Natl. Acad. Sci. USA 104:3306-3311.

29. Griffith, G. W., and Shaw, D. S. 1998. Polymorphisms in Phytophthora infestans: Four mitochondrial haplotypes are detected after PCR amplification of DNA from pure cultures or from host lesions. Appl. Environ. Microbiol. 64:4007-4014.

30. Grünwald, N. J., and Flier, W. G. 2005. The biology of Phytophthora infestans at its center of origin. Annu. Rev. Phytopathol. 43:171-190.

31. Grünwald, N. J., Sturbaum, A. K., Romero Montes, G., Garray Serrano, E., Lozoya-Saldaña, H., and Fry, W. E. 2006. Selection for fungicide resistance within a growing season in field populations of Phytophthora infestans at the center of origin. Phytopathology 96:1397-1403.

32. Guo, J., van der Lee, T., Qu, D. Y., Yao, Y. Q., Gong, X. F., Liang, D. L., Xie, K. Y., Wang, X. W., and Govers, F. 2009. Phytophthora infestans isolates from Northern China show high virulence diversity but low genotypic diversity. Plant Biol. 11:57-67.

33. Jiang, R. H. Y., Tripathy, S., Govers, F., and Tyler, B. M. 2008. The RXLR effector reservoir in two Phytophthora species is dominated by a single rapidly evolving super-family with more than 700 members. Proc. Natl. Acad. Sci. USA 105:4874-4879.

34. Knapova, G., and Gisi, U. 2002. Phenotypic and genotypic structure of Phytophthora infestans populations on potato and tomato in France and Switzerland. Plant Pathol. 51:641-653.

35. Knapova, G., Tenzer, I., Gessler, C., and Gisi, U. 2001. Characterization of Phytophthora infestans from potato and tomato with molecular markers. Pages 6-9 in: Proc. 5th Congr. Eur. Foundation Plant Pathol. (Biodiversity in Plant Pathology). SIVP, Taormina, Italy.

36. Lees, A. K., Wattier, R., Shaw, D. S., Sullivan, L., Williams, N. A., and Cooke, D. E. L. 2006. Novel microsatellite markers for the analysis of Phytophthora infestans populations. Plant Pathol. 55:311-319.

37. Lehtinen, A., and Hannukkala, A. 2004. Oospores of Phytophthora infestans in soil provide an important new source of primary inoculums in Finland. Agric. Food Sci. 13:399-410.

38. Lehtinen, A., Hannukkala, A., Andersson, B., Hermansen, A., Le, V. H., Nærstad, R., Brurberg, M. B., Nielsen, B. J., Hansen, J. G., and Yuen, J. 2008. Phenotypic variation in Nordic populations of Phytophthora infestans in 2003. Plant Pathol. 57:227-234.

39. May, K. J., and Ristaino, J. B. 2004. Identity of the mtDNA haplotype(s) of Phytophthora infestans in historical specimens from the Irish Potato Famine. Mycol. Res. 108:471-479.

40. Möller, K., Dilger, M., Habermeyer, J., Zinkernagel, V., Flier, W. G., and Hausladen, H. 2009. Population studies on Phytophthora infestans on potatoes and tomatoes in southern Germany. Eur. J. Plant Pathol. 124:659672.

41. Niederhauser, J. S. 1991. Phytophthora infestans-the Mexican connection. Pages 272-294 in: Phytophthora. J. A. Lucas, R. C. Shattock, D. S. Shaw, and L. R. Cooke, eds. Cambridge University Press, Cambridge.

42. Oliva, R. F., Kroon, L. P. N. M., Chacón, G., Flier, W. G., Ristaino, J. B., and Forbes, G. A. 2010. Phytophthora andina sp. nov., a newly identified heterothallic pathogen of solanaceous hosts in the Andean highlands. Plant Pathol. 59:613-625.

43. Oyarzun, P. J., Pozo, A., Ordoñez, M. E., Doucett, K., and Forbes, G. A. 1998. Host specificity of Phytophthora infestans on tomato and potato in Ecuador. Phytopathology 88:265-271

44. Pérez, W. G., Gamboa, J. S., Falcon, Y. V., Coca, M., Raymundo, R. M., and Nelson, R. J. 2001. Genetic structure of Peruvian populations of Phytophthora infestans. Phytopathology 91:956-965.

45. Pérez, W., Lara, J., and Forbes, G. A. 2009. Resistance to metalaxyl-M and cymoxanil in a dominant clonal lineage of Phytophthora infestans in Huánuco, Peru, an area of continuous potato production. Eur. J. Plant Pathol. 125:87-95.

46. Reis, A., Smart, C. D., Fry, W. E., Maffia, L. A., and Mizubuti, E. S. G. 2003. Characterization of isolates of Phytophthora infestans from southern and southeastern Brazil from 1998 to 2000. Plant Dis. 87:896-900. 
47. Sozzi, D. F., Schwinn, J., and Gisi, U. 1992. FRAC methods for monitoring the sensitivity of fungal pathogens to phenylamide fungicides, developed by the Phenylamide Fungicide Resistance Action Committee (PA-FRAC) of GIFAP. 2. Determination of the sensitivity of Phytophthora infestans to phenylamides: A leaf disc method. EPPO Bull. 22:306-309.

48. Suassuna, N. D., Maffia, L. A., and Mizubuti, E. S. G. 2004. Aggressiveness and host specificity of Brazilian isolates of Phytophthora infestans. Plant Pathol. 53:405-413.

49. Vargas, A. M., Quesada Ocampo, L. M., Céspedes, M. C., Carreño, N., González, A., Rojas, A., Zuluaga, A. P., Myers, K., Fry, W. E., Jiménez,
P., Bernal, A. J., and Restrepo, S. 2009. Characterization of Phytophthora infestans populations in Colombia: First report of the A2 mating type. Phytopathology 99:82-88.

50. Wangsomboondee, T., Groves, C. T., Shoemaker, P. B., Cubeta, M. A., and Ristaino, J. B. 2002. Phytophthora infestans populations from tomato and potato in North Carolina differ in genetic diversity and structure. Phytopathology 92:1189-1195.

51. Widmark, A.-K., Andersson, B., Cassel-Lundhagen, A., Sandström, M., and Yuen, J. E. 2007. Phytophthora infestans in a single field in southwest Sweden early in spring: Symptoms, spatial distribution and genotypic variation. Plant Pathol. 56:573-579. 